\title{
Rancang Bangun Game Labirin Hijaiyah Dengan Unity Menggunakan Metode Finite State Machine
}

\author{
Khoirul Solekhan Arif, Mohamad Hendra Sugiharto, Fresy Nugroho, Juniardi Nur Fadilah \\ Teknik Informatika, Universitas Islam Negeri Maulana Malik Ibrahim Malang \\ Email: khoirulsa1997@gmail.com
}

\begin{abstract}
Abstrak
Pengenalan huruf hijaiyah sejak dini adalah hal yang penting. Salah satu media yang dapat digunakan adalah game. Game yang dirancang adalah game labirin hijaiyah yang bertujuan untuk memperkenalkan huruf-huruf hijaiyah. Game ini dirancang menggunakan Unity dan menerapkan metode Finite State Machine pada karakter-karakternya. Metode yang digunakan dalam penelitian ini adalah metode Waterfall. Hasil yang diperoleh adalah game labirin hijaiyah dapat dimainkan dengan baik.
\end{abstract}

Kata Kunci : Game, Huruf Hijaiyah, Unity, Finite State Machine

Abstract. Early recognition of hijaiyah letters is important. Game is one of the media that can be used. The designed game is the Labirin Hijaiyah game that aims to introduce hijaiyah letters. This game is designed using Unity and applies the Finite State Machine method to its characters. The method used in this study is the Waterfall method. The results obtained are that the Labirin Hijaiyah game can be played well.

Keywords : Game, Hijaiyah Letters, Unity, Finite State Machine

\section{PENDAHULUAN}

Bagi pemeluk agama islam mengenal huruf-huruf hijaiyah sejak dini adalah hal yang penting. Hal ini dikarenakan mengenal huruf hijaiyah merupakan hal dasar dalam belajar membaca Al-Qur'an. Akan tetapi pada saat ini minat orang untuk belajar dan mengenal huruf hijaiyah cukup rendah.

Rendahnya minat belajar dan mengenal huruf-huruf hijaiyah ini dikarenakan beberapa faktor. Faktorfaktor tersebut misalnya adalah metode pengajaran yang monoton dan membosankan, media pengajaran yang tidak menarik dan faktor-faktor lain. Oleh karena perlu adanya suatu inovasi yang dapat membuat orang tertarik untuk mengenal huruf-huruf hijaiyah. Oleh karena itu pada penelitian ini dirancang game labirin hijaiyah untuk mengenalkan huruf-huruf hijaiyah dengan lebih menarik.

Pada game labirin hijaiyah ini pemain harus mengumpulkan huruf-huruf hijaiyah dan menghindari musuh agar bisa menyelesaikan permainan dan naik ke level berikutnya. Game ini dirancang menggunakan Unity dan menggunakan metode Finite State Machine pada karakter-karakternya sehingga game menjadi lebih menarik untuk dimainkan.

\section{LANDASAN TEORI \\ Rancang Bangun}

Rancang Bangun adalah penggambaran, perencanaan, dan pembuatan sketsa atau pengaturan dari beberapa elemen yang terpisah ke dalam suatu kesatuan yang utuh dan berfungsi atau dapat juga didefinisikan sebagai kegiatan menerjemahkan hasil analisis ke dalam bentuk paket perangkat lunak kemudian menciptakan sistem tersebut atau memperbaiki sistem yang sudah ada(Syukroni, 2017).

\section{Game}

Game adalah mode interaksi antara pemain, mesin dengan tampilan visual elektronik, dan mungkin pemain lain, yang dimediasi oleh konteks fiksi yang bermakna, dan ditopang oleh ikatan 
emosional antara pemain dan hasil dari tindakannya dalam konteks fiksi ini(Arjoranta, 2019).

\section{Huruf Hijaiyah}

Huruf hijaiyah adalah huruf yang digunakan oleh pemeluk agama islam untuk membaca Al-Qur'an. Huruf hijaiyah yang umumnya diketahui adalah berjumlah 30 huruf(Efendi, Purwandari, \& Aziz, 2015). Huruf-hurufnya yaitu seperti pada Gambar 1.

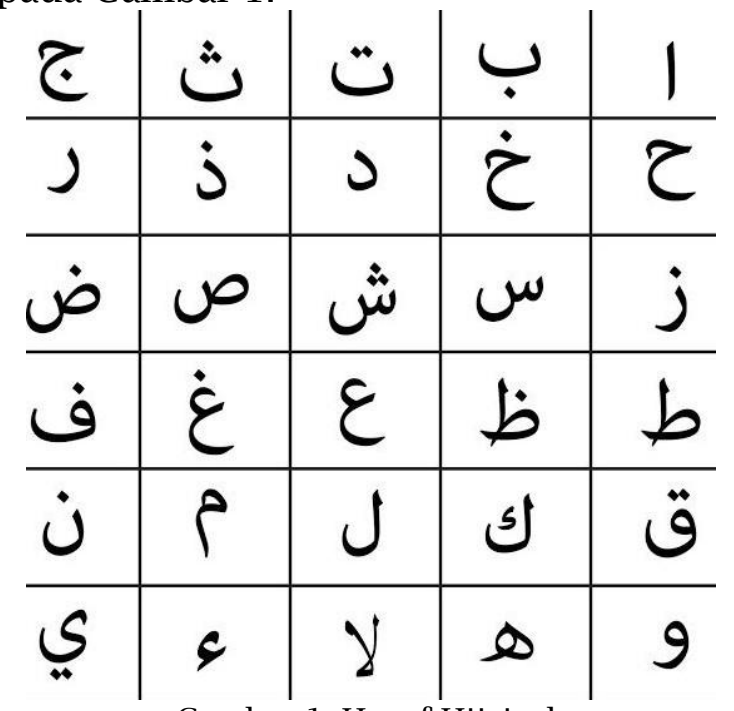

Gambar 1. Huruf Hijaiyah

Unity

Unity adalah platform pengembangan lintas platform yang awalnya dibuat untuk mengembangkan game tetapi sekarang digunakan untuk berbagai hal seperti arsitektur, seni, aplikasi anakanak, manajemen informasi, pendidikan, hiburan, pemasaran, medis, militer, instalasi fisik, simulasi, pelatihan dan banyak lagi.

Unity membutuhkan banyak kompleksitas dalam mengembangkan game dan pengalaman interaktif serupa dan terlihat setelah mereka di belakang layar sehingga orang dapat melanjutkan mendesain dan mengembangkan game mereka. Kompleksitas ini termasuk rendering grafik, fisika dunia, dan kompilasi. Pengguna yang lebih maju dapat berinteraksi dan menyesuaikannya sesuai kebutuhan, tetapi untuk pemula mereka tidak perlu khawatir.

Game dalam Unity dikembangkan dalam dua bagian yaitu bagian pertama di dalam editor Unity dan bagian kedua menggunakan kode, khususnya C\#. Unity dibundel dengan MonoDevelop atau Visual Studio 2015 Community untuk menulis C\#(CS4HS 2016 The University of Queensland, 2016).

Finite State Machine

Finite State Machine adalah metode yang dapat digunakan untuk memodelkan perilaku karakter di dalam game berdasarkan keadaan yang sudah ditentukan. Transisi keadaan pada Finite State Machine lebih rumit dan urutannya menunjukkan tidak ada pola yang sederhana dan teratur, seperti pada counter atau shift register. Logika keadaan berikutnya harus dibangun dari awal dan kadang-kadang dikenal sebagai logika acak.

Secara formal, Finite State Machine ditentukan oleh lima entitas yaitu status simbolik, sinyal input, sinyal output, fungsi keadaan berikutnya dan fungsi output. Suatu keadaan menunjukkan kondisi internal yang unik dari suatu sistem. Seiring berjalannya waktu, Finite State Machine transit dari satu keadaan ke keadaan lain. Keadaan baru ditentukan oleh fungsi keadaan berikutnya yang mana merupakan fungsi dari keadaan saat ini dan sinyal input. Dalam sebuah Synchronous Finite State Machine, transisi dikontrol oleh sinyal jam dan hanya dapat terjadi di tepi pemicu jam.

Fungsi output menentukan nilai sinyal output. Jika itu adalah fungsi dari keadaan saja, output dikenal sebagai output Moore. Di sisi lain, jika itu adalah fungsi dari keadaan dan sinyal input, output dikenal sebagai output Mealy. Finite State Machine disebut Moore machine atau Mealy machine jika hanya berisi output Moore atau output Mealy secara berturut-turut. Finite State Machine yang kompleks biasanya memiliki kedua jenis output tersebut(Chu, 2006).

\section{METODOLOGI PENELITIAN}

Metode yang digunakan pada penelitian ini adalah menggunakan metode Waterfall. Berikut tahapan-tahapannya :

1. Analisa kebutuhan Pada tahap ini peneliti melakukan analisa kebutuhan perangkat lunak seperti Unity dan studi-studi literatur yang dibutuhkan seperti tentang game, huruf hijaiyah dan lain sebagainya.

2. Desain Sistem 
Pada tahap ini dilakukan proses desain dimana dimulai dengan merancang storyboard dan karakter yang akan digunakan dalam game.

3. Pembuatan Sistem

Pada tahap ini dilakukan proses pembuatan sistem di dalam game dengan menggunakan Unity dan penggunaan metode Finite State Machine pada perilaku karakterkarakternya.

4. Pengujian Sistem

Pada tahap ini dilakukan pengujian Black Box Testing untuk mengidentifikasi apakah tomboltombol dan menu di dalam game dapat berjalan baik atau tidak sehingga apabila ditemukan kesalahan dapat segera diperbaiki.

5. Pemeliharaan Sistem

Pada tahap ini dilakukan pemeliharaan secara berkala untuk memperbaiki kesalahan yang tidak teridentifikasi pada tahap sebelumnya.

\section{HASIL DAN PEMBAHASAN \\ Penerapan Finite State Machine Pada Musuh}

Finite State Machine yang diterapkan pada musuh yaitu musuh akan mengejar player ketika player mendekat dan apabila player tidak mendekat maka musuh akan tetap diam.

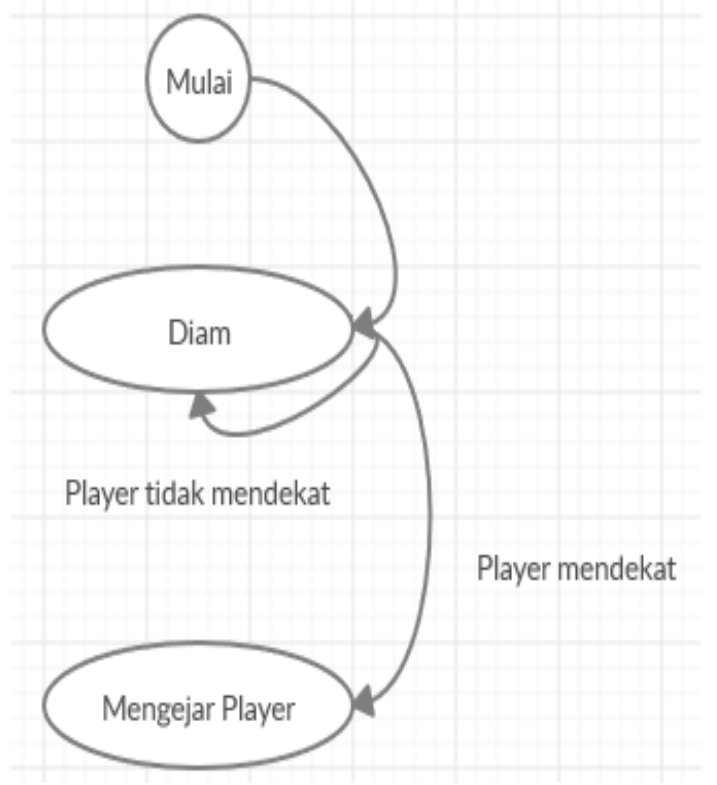

Gambar 2. Finite State Machine Pada Musuh

\section{Penerapan Finite State Machine Pada Player}

Finite State Machine yang diterapkan pada player yaitu player harus mencari huruf hijaiyah. Apabila bertemu musuh maka player harus menghindar agar darahnya berkurang dan mati. Apabila player menemukan huruf hijaiyah maka player harus mengambil huruf hijaiyah tersebut. Jika jumlah huruf hijaiyah yang terkumpul belum sesuai dengan yang sudah ditentukan maka player harus mengumpulkan huruf hijaiyah hingga huruf hijaiyah yang terkumpul sesuai dengan yang sudah ditentukan agar player dapat keluar dari labirin dan menuju ke level berikutnya.

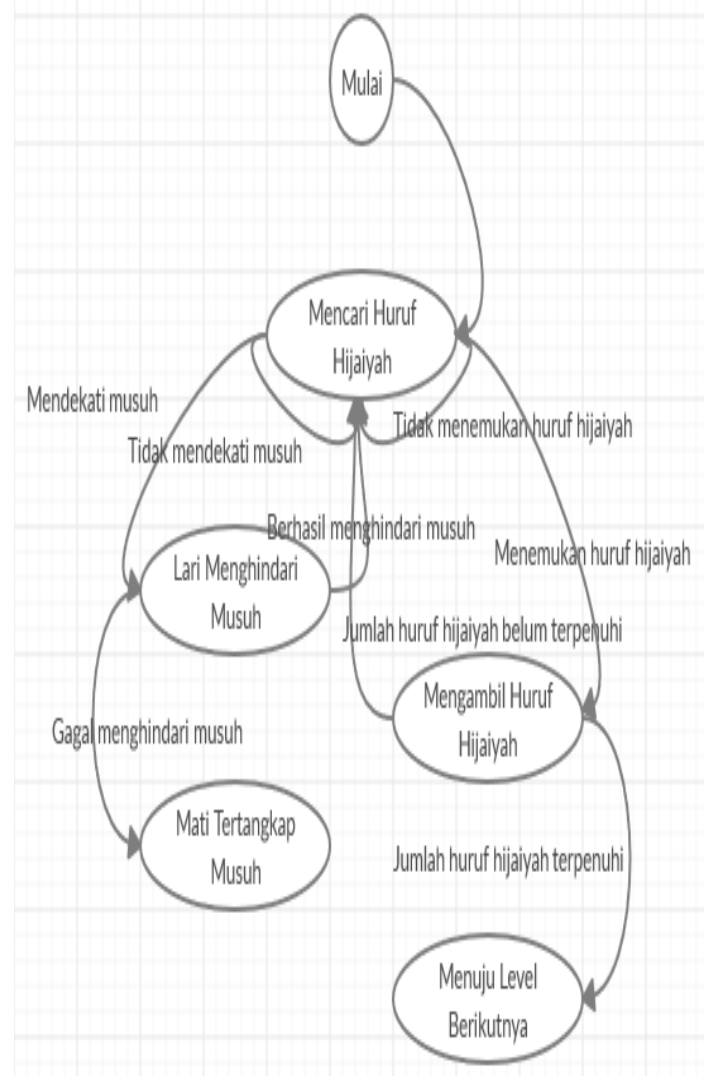

Gambar 3. Finite State Machine Pada Player

\section{Tampilan Menu Utama}

Pada Menu Utama terdapat 5 tombol yaitu tombol Mulai, tombol Petunjuk, tombol Pengaturan, tombol Tentang dan tombol Keluar. Tombol-tombol tersebut memiliki fungsi sebagai berikut :

1. Tombol Mulai 
Tombol ini digunakan untuk memulai permainan.

2. Tombol Petunjuk

Tombol ini digunakan untuk mengetahui petunjuk-petunjuk dalam memainkan game.

3. Tombol Pengaturan

Tombol ini digunakan untuk melakukan pengaturan-pengaturan pada game.

4. Tombol Tentang

Tombol ini digunakan untuk mengetahui informasi-informasi mengenai game.

5. Tombol Keluar

Tombol ini digunakan untuk keluar dari permainan.

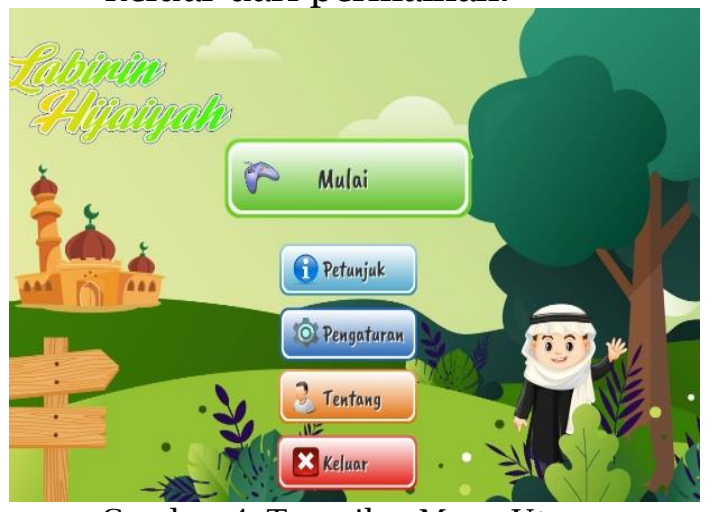

Gambar 4. Tampilan Menu Utama

Tampilan Posisi Awal Player di dalam

\section{Game}

Ketika tombol Mulai diklik maka player akan masuk ke dalam game seperti pada Gambar 5.

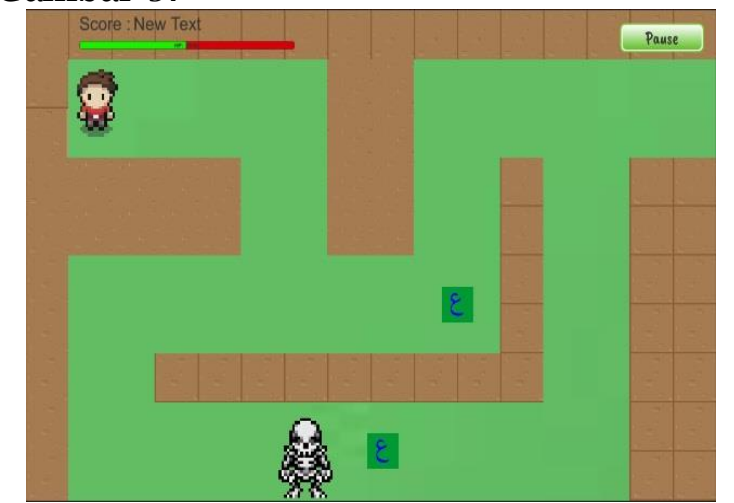

Gambar 5. Tampilan Posisi Awal Player di dalam Game

Tampilan Musuh mengejar Player Ketika Player mendekati musuh maka musuh akan mengejar player dan mengurangkan darah player.

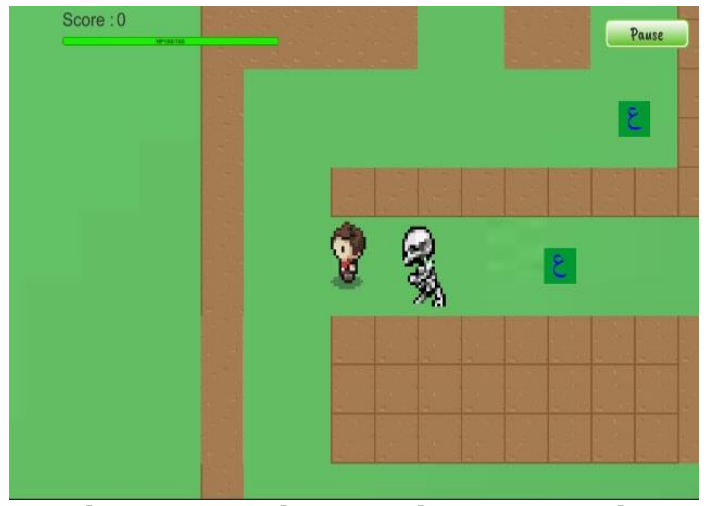

Gambar 6. Tampilan Musuh mengejar Player

\section{Tampilan Player mengambil Huruf Hijaiyah}

Ketika player mengambil huruf hijaiyah maka player akan mendapat skor yang telah ditentukan sebelumnya.

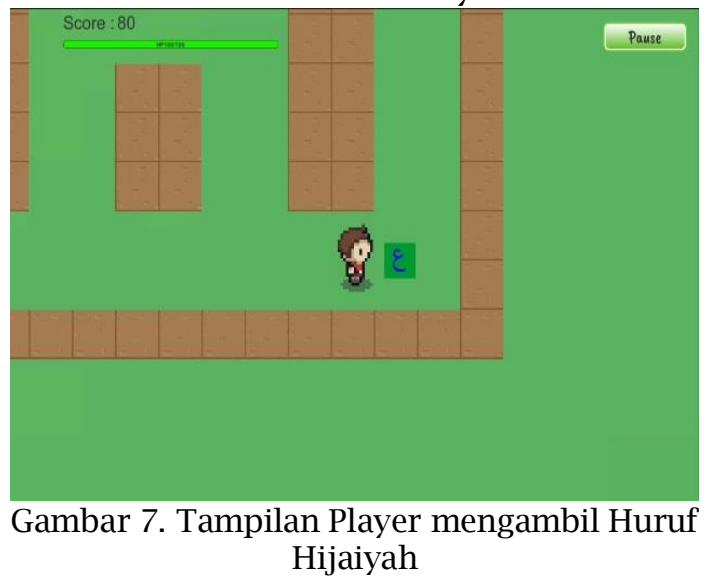

\section{Tampilan Game Over}

Ketika darah player habis maka player akan mati dan game akan selesai (game over).

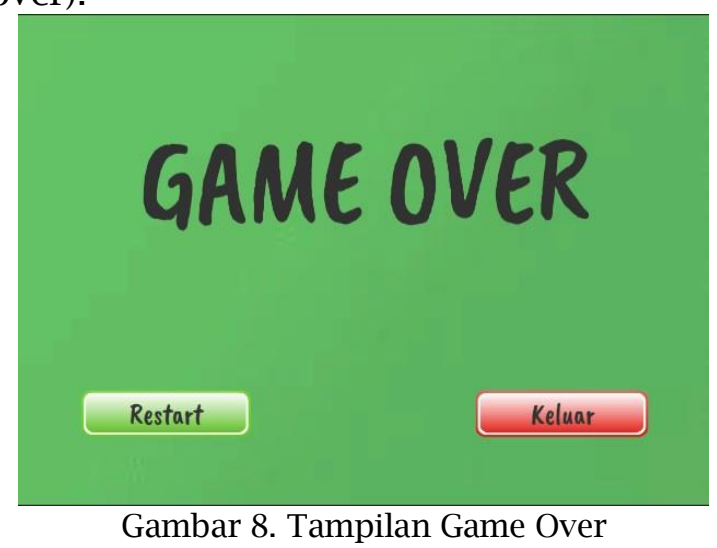

Tampilan Player Berhasil

Ketika player sudah mengumpulkan jumlah huruf hijaiyah yang sesuai dengan yang telah ditentukan maka player akan berhasil dan menuju pada level berikutnya. 


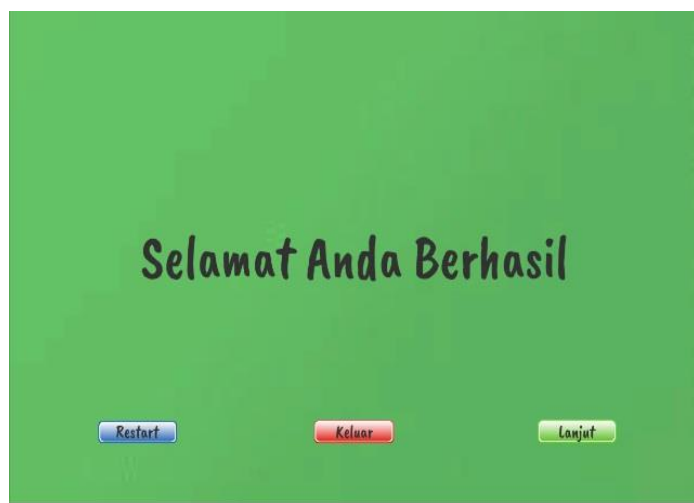

Gambar 9. Tampilan Player Berhasil

\section{KESIMPULAN DAN SARAN}

Dari pembahasan diatas dapat disimpulkan bahwa metode Finite State Machine dapat diterapkan pada karakterkarakter di game labirin hijaiyah. Game yang telah dibuat juga dapat dimainkan dengan baik dan dapat dijadikan sebagai media pengenalan huruf-huruf hijaiyah.

Selain itu, saran yang dapat diberikan adalah peningkatan kualitas game terutama dalam hal tampilan visual dan penambahan algoritma-algoritma kecerdasan buatan pada musuh agar game menjadi lebih menarik untuk dimainkan.

\section{DAFTAR PUSTAKA}

Arjoranta, J. (2019). How to Define Games and Why We Need to. The Computer Games Journal. https://doi.org/10.1007/s40869-01900080-6

Chu, P. P. (2006). RTL Hardware Design Using VHDL: Coding for Efficiency, Portability, and Scalability. In RTL Hardware Design Using VHDL: Coding for Efficiency, Portability, and Scalability. https://doi.org/10.1002/0471786411 CS4HS 2016 The University of Queensland. (2016).

Efendi, R., Purwandari, E. P., \& Aziz, M. A. (2015). APLIKASI PENGENALAN HURUF HIJAIYAH BERBASIS MARKER AUGMENTED REALITY PADA PLATFORM ANDROID. Pseudocode. https://doi.org/10.33369/pseudocode. 2.2.124-134

Syukroni, M. F. (2017). Rancang Bangun Knowledge Management Sistem Berbasis Web Pada Madrasah Mualimin Al-Islamiyah Uteran Geger Madiun. Teknik Informatika Universitas Muhammadiyah Ponorogo. 